\title{
Limits of mass transfer in parallel-plate dialysers
}

\author{
Spas D Kolev ${ }^{1, *}$ and Willem E van der Linden \\ Laboratory for Chemical Analysis, Department of Chemical Technology, Unversity of Twente, PO Box 217, \\ NL-7500 AE Enschede (Netherlands)
}

(Recelved 18th June 1991)

\begin{abstract}
The absolute limits of mass transfer across the membrane in a parallel-plate dialyser set by the flow pattern in both channels were determıned on the basis of a mathematical model assuming axially dispersed plug flow The lower limit corresponds to the case of mass transfer under laminar flow conditions For determination of the upper limit for the same values of the parameters influencing the flow regime (e $g$, flow-rate, mean residence tıme), plug flow and instant restoration of the transverse concentration uniformity, disturbed by the mass-transfer process, were assumed This case corresponds to infinitely high Peclet numbers and mass-transfer coefficients (Sherwood numbers) in both channels For a particular gross flow pattern in the channels (1 e, residence time distribution), characterized by non-zero axial dispersion, the lower limit will coincide again with the laminar case However, the upper limit in such a case will correspond to infinitely high mass-transfer coefficients but finite Peclet numbers and will be lower than the absolute upper limit of the dialyser mentioned above The results obtained allow the estımation of the range withın which the mass transfer in real parallel-plate dialysers can be expected
\end{abstract}

Keywords Flow system, Dialysis, Mass transfer, Mathematical modelling

Parallel-plate flow-through dialysers are the key elements in various industrial mass-exchange apparatus [1], artificial kıdneys used for blood dialysis [2] and recently in flow-ınjection manıfolds where separation of the analyte is aimed for [3] As in most flow-through apparatus, the flow pattern plays a very important role in the performance of parallel-plate dialysers The influence of their most important parameters ( $1 \mathrm{e}$, geometric dimensions, flow-rate and physical properties of the phases) on the mass-transfer process in the case of fully developed laminar flow in both channels was reported earlier [4,5] It should be taken into consideration that the ideal laminar flow is the most unfavourable for the performance of the flow pattern because the transverse mass transport in this instance is due only to diffusion For

\footnotetext{
1 Permanent address Faculty of Chemistry, University of
} Sofia, Anton Ivanov Ave 1, BG-1126 Sofia, Bulgaria this reason, it can be stated that for a given set of parameter values the ideal laminar flow pattern sets the lower limit of transfer across the membrane Although the Reynolds numbers in both channels are in the laminar flow region for most industrial parallel-plate dialysers and always in those applied for haemodialysis or in flow-injection manifolds, local turbulences can be generated This can be realized in various ways, the most frequently used being by turbulence promoters of different kinds [6-9] It can be expected that the performance of the low-Reynolds-number dialysers could be improved to a considerable extent by such an approach because the transverse convective transport involved will reduce the mass-transfer resistance in the channels An important question arising in this respect is the extent to which the overall masstransfer can be enhanced in this manner provided that the parameters of the dialyser except for the 
flow pattern remain unchanged The answer will set the upper lımit for the mass transfer across the membrane for this set of parameter values $A$ related problem is the possibility of predicting the range within which the concentrations of the solute in both channels of the dialyser will be, provided that in the absence of mass exchange their gross flow pattern is known

\section{THEORETICAL CONSIDERATIONS}

The subsequent considerations are based on the assumption that the membrane is a solid-state element of the dialyser, such as its walls, so that the flow pattern in both channels cannot affect the nature of the mass transfer within the mem- brane As mentioned above, the lower limit of mass transfer in a parallel-plate dialyser with respect to the flow pattern in both channels will correspond to the casc of lammar flow, while the upper limit will be reached if ideal plug flow with an infinitely high mass-transfer coefficient is established in each channel These two limiting cases will be considered under steady-state cond1tions The former case was numerically solved in the transient case using operational calculus [5], but this solution is complicated whereas under steady-state conditions a much simpler analytical solution can be obtained

\section{Fully developed laminar flow}

The steady-state mass-transfer in a parallelplate dialyser, presented schematically in Fig 1,

TABLE 1

Symbols and definitions ${ }^{a}$

\begin{tabular}{|c|c|}
\hline$a$ & Half of a channel height (m) \\
\hline$A$ & $=a_{\mathrm{a}} / a_{\mathrm{d}}$ \\
\hline c & Mean concentration in the cross-section of the flow $\left(\mathrm{mol} \mathrm{m}^{-3}\right)$ \\
\hline$c_{\mathrm{o}}$ & Concentration in the donor stream at $x=0\left(\mathrm{~mol} \mathrm{~m}^{-3}\right)$ \\
\hline$c_{\mathrm{dm}}$ & Concentration at the donor stream $/$ membrane interface $\left(\mathrm{mol} \mathrm{m}^{-3}\right)$ \\
\hline$c_{d m}$ & Concentration at the acceptor stream/membrane interface $\left(\mathrm{mol} \mathrm{m}^{-3}\right)$ \\
\hline C & $=c / c_{\mathrm{o}}$ Dimensionless concentration \\
\hline$D$ & Molecular diffusion coefficient $\left(\mathrm{m}^{2} \mathrm{~s}^{-1}\right)$ \\
\hline$D_{\mathrm{L}}$ & Axıal-dispersion coefficient $\left(\mathrm{m}^{2} \mathrm{~s}^{-1}\right)$ \\
\hline$D_{\mathrm{md}}$ & $=D_{\mathrm{m}} / D_{\mathrm{d}}$ \\
\hline$D_{\mathrm{dd}}$ & $=D_{\mathrm{a}} / D_{\mathrm{d}}$ \\
\hline$F$ & Distribution coefficient \\
\hline$g$ & Coefficient defined by Eqn 9 \\
\hline$k$ & Mass-transfer coefficient $\left(\mathrm{m} \mathrm{s}^{-1}\right)$ \\
\hline$K$ & $=k L /(2 \bar{u} a)$ Dimensionless mass-transfer coefficient \\
\hline$L$ & Characterıstıc length $(\mathrm{m})$ \\
\hline$P$ & $=u L / D_{L}$ Peclet number \\
\hline$Q$ & $=\Delta / D_{\mathrm{md}}$ \\
\hline$u$ & Mean linear flow-rate $\left(\mathrm{m} \mathrm{s}^{-1}\right)$ \\
\hline$U$ & $=u_{\mathrm{a}} / u_{\mathrm{d}}$ \\
\hline$x$ & Axıal distance (m) \\
\hline$x$ & $=x / L$ Dimensionless axial distance \\
\hline$y$ & Distance normal to the axial distance $(\mathrm{m})$ \\
\hline$Y$ & $=y / a_{\mathrm{d}}$ Dimensionless distance normal to the axıal distance \\
\hline \multicolumn{2}{|c|}{ Greek letters } \\
\hline$\alpha$ & Coefficient defined by Eqn 10 \\
\hline$\beta$ & Negative root of Eqn 8 \\
\hline $\boldsymbol{\delta}$ & Half-width of the membrane (m) \\
\hline$\Delta$ & $=\delta / a_{\mathrm{d}}$ Dimensionless half-width of the membrane \\
\hline$\tau$ & $=D_{\mathrm{d}} L /\left(u_{\mathrm{d}} a_{\mathrm{d}}^{2}\right)$ Fourier number of the donor stream \\
\hline
\end{tabular}

a Subscripts $\mathrm{d}$, a and $\mathrm{m}$ refer to the donor stream, the acceptor stream and the membrane, respectively 


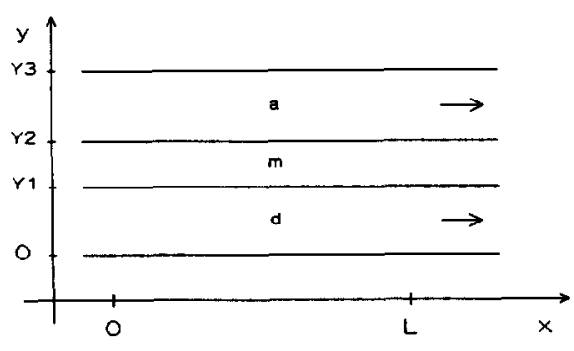

Fig 1 Scheme of a parallel-plate dialyser $\mathrm{Y} 1=2 a_{\mathrm{d}}, \mathrm{Y} 2=$ $2\left(a_{\mathrm{d}}+\delta\right), \mathrm{Y} 3=2\left(a_{\mathrm{d}}+\delta+a_{\mathrm{a}}\right), \mathrm{d}, \mathrm{m}$ and a refer to donor stream, membrane and acceptor stream, respectively

can be described on the basis of the axially dispersed plug-flow model by the following two ord1nary differential equations in dimensionless quantities and variables

$$
\begin{aligned}
& \frac{\mathrm{d}^{2} C_{\mathrm{d}}}{\mathrm{d} X^{2}}-P_{\mathrm{d}}\left(\frac{\mathrm{d} C_{\mathrm{d}}}{\mathrm{d} X}\right)-K_{\mathrm{d}} P_{\mathrm{d}}\left(C_{\mathrm{d}}-C_{\mathrm{dm}}\right)=0 \\
& \frac{\mathrm{d}^{2} C_{\mathrm{a}}}{\mathrm{d} X^{2}}-P_{\mathrm{a}}\left(\frac{\mathrm{d} C_{\mathrm{a}}}{\mathrm{d} X}\right)-K_{\mathrm{a}} P_{\mathrm{a}}\left(C_{\mathrm{am}}-C_{\mathrm{a}}\right)=0
\end{aligned}
$$

where the symbols and their definitions are given in Table 1

With a constant concentration of the solute in the donor stream at the inlet of the dialyser $(X=0)$, the dimensionless boundary conditions of Eqns 1 and 2 will be as follows at $X=0$

$C_{\mathrm{d}}(0)=10$ and $C_{\mathrm{a}}(0)=00$

at $\mathrm{X} \rightarrow \infty$

$C_{\mathrm{d}}(\infty)=00$ and $C_{\mathrm{a}}(\infty)=00$

The concentration distribution in the membrane, neglecting axial diffusion, is described by the steady-state solution of the one-dimensional Fick's second law

$$
\begin{aligned}
C_{\mathrm{m}}= & \frac{2(1+\Delta) F_{\mathrm{d}} C_{\mathrm{dm}}-2 F_{\mathrm{a}} C_{\mathrm{am}}}{2 \Delta} \\
& +\left(\frac{F_{\mathrm{a}} C_{\mathrm{am}}-F_{\mathrm{d}} C_{\mathrm{dm}}}{2 \Delta}\right) Y
\end{aligned}
$$

where $\Delta$ is the dimensionless half-width of the membrane and $F_{\mathrm{d}}$ and $F_{\mathrm{a}}$ are the distribution coefficients of the solute between the membrane and the donor and acceptor streams, respectively On the basis of the condition for continuity of the solute fluxes across the membrane, it can be written that

$K_{\mathrm{d}}\left(C_{\mathrm{d}}-C_{\mathrm{dm}}\right)=U A K_{\mathrm{a}}\left(C_{\mathrm{am}}-C_{\mathrm{a}}\right)$

and

$\frac{4 K_{\mathrm{d}} \Delta}{D_{\mathrm{md}} \tau}\left(C_{\mathrm{d}}-C_{\mathrm{dm}}\right)=F_{\mathrm{d}} C_{\mathrm{dm}}-F_{\mathrm{a}} C_{\mathrm{am}}$

where $D_{\text {md }}$ is the ratio between the diffusion coefficients of the solute in the membrane and in the donor stream, $\tau$ is the Fourier number of the donor stream and $U$ and $A$ are the ratios between the flow-rates and the heights of the donor and the acceptor channels, respectively

Equations 4 and 5 allow the surface concentrations $C_{\mathrm{dm}}$ and $C_{\mathrm{am}}$ to be expressed as functions of $C_{\mathrm{d}}$ and $C_{\mathrm{a}}$, which can be subsequently subst1tuted in Eqns 1 and 2 The resulting differential equations can be solved by an operational approach [10] and, taking into consideration their boundary conditions, the solutions for $C_{\mathrm{d}}$ and $C_{\mathrm{a}}$ will be

$C_{\mathrm{d}}=\frac{\alpha}{\alpha-F_{\mathrm{d}} / F_{\mathrm{a}}}\left[1-\frac{F_{\mathrm{d}}}{\alpha F_{\mathrm{a}}} \exp (\beta X)\right]$

and

$C_{\mathrm{a}}=\frac{\alpha}{\alpha F_{\mathrm{d}} / F_{\mathrm{a}}-1}[1-\exp (\beta X)]$

The coefficient $\beta$ is the only negative root of Eqn 8 and can be calculated analytically by Cardan's equation [11]

$$
\begin{aligned}
& z^{3}-\left(P_{\mathrm{d}}+P_{\mathrm{a}}\right) y^{2}+\left[P_{\mathrm{d}} P_{\mathrm{a}}-g\left(U A F_{\mathrm{d}} P_{\mathrm{d}}+F_{\mathrm{a}} P_{\mathrm{a}}\right)\right] z \\
& +g P_{\mathrm{d}} P_{\mathrm{a}}\left(U A F_{\mathrm{d}}+F_{\mathrm{a}}\right)=0
\end{aligned}
$$

where

$g=\left[\frac{F_{\mathrm{a}}}{K_{\mathrm{a}}}+U A\left(\frac{F_{\mathrm{d}}}{K_{\mathrm{d}}}\right)+U A\left(\frac{4 \Delta}{D_{\mathrm{md}} \tau}\right)\right]^{-1}$

Once determined, $\beta$ can be used later for calculating the coefficient $\alpha$ in Eqns 6 and 7

$$
\alpha=\frac{\beta}{U A F_{\mathrm{a}} g}\left(1-\frac{\beta}{P_{\mathrm{d}}}\right)+\frac{F_{\mathrm{d}}}{F_{\mathrm{a}}}
$$

It was shown that in the case of fully developed laminar flow, the Peclet numbers and the 
mass-transfer coefficients of both streams can be calculated by the following relationshıps [5]

$P_{\mathrm{d}}=525 \tau$

$P_{\mathrm{a}}=D_{\text {ad }} P_{\mathrm{d}} /\left(U A^{2}\right)$

$K_{\mathrm{d}}=0175+0614 \tau$

$K_{\mathrm{a}}=0175+0614 D_{\mathrm{ad}} \tau /\left(U A^{2}\right)$

\section{Plug flow}

According to this extreme case, the masstransfer coefficients and the Peclet numbers of both the donor and the acceptor streams must be infinitely high, 1 e $, P_{\mathrm{d}} \rightarrow \infty, P_{\mathrm{a}} \rightarrow \infty, K_{\mathrm{d}} \rightarrow \infty$ and $K_{\mathrm{a}} \rightarrow \infty$ If the necessary substitutions in Eqns 8-10 are performed, it can be found that

$\alpha=-1 /(U A)$

and

$\beta=-\frac{D_{\mathrm{md}} \tau}{4 \Delta}\left(F_{\mathrm{d}}+F_{\mathrm{a}} /(U A)\right)$

After substituting the equations for $\alpha$ and $\beta$ (Eqns 15 and 16) in Eqns 6 and 7, the steadystate concentrations in both the donor and the acceptor streams can be calculated

\section{Axzally duspersed plug flow}

In real flow-through systems, ideal plug flow cannot be created and the Peclet numbers have finite values which are greater than or equal to those corresponding to fully developed laminar flow (Eqns 11 and 12) An important problem concerning the performance of parallel-plate dialysers is the possibility of predicting the range within which the value of the degree of transfer (1 e , $C_{\mathrm{a}} / C_{\mathrm{d}}$ ) can be expected, provided that the gross flow pattern in both channels in the absence of mass exchange is known The highest possible mass transfer in this case will be reached If again both mass-transfer cocfficients $\left(1 \mathrm{e}, K_{\mathrm{d}}\right.$ and $K_{\mathrm{a}}$ ) are infinitely high Equations 6-8 and 10 can be used for calculatıng the steady-state concentrations in both channels, taking into consideration that $g=D_{\mathrm{md}} \tau /(4 \Delta U A)$ It was shown that under steady-state conditions the performance of a parallel-plate dialyser is determined mainly by the values of its mass-transfer coefficients [5], so that it can be expected that the maximum mass transfer for finite Peclet numbers will be very close to the ideal plug flow case considered earlier

\section{Illustrative example}

The performance of a dialyser under steadystate conditions can be characterized by the degree of transfer $(E)$, defined as the ratio between the concentrations in the acceptor and the donor
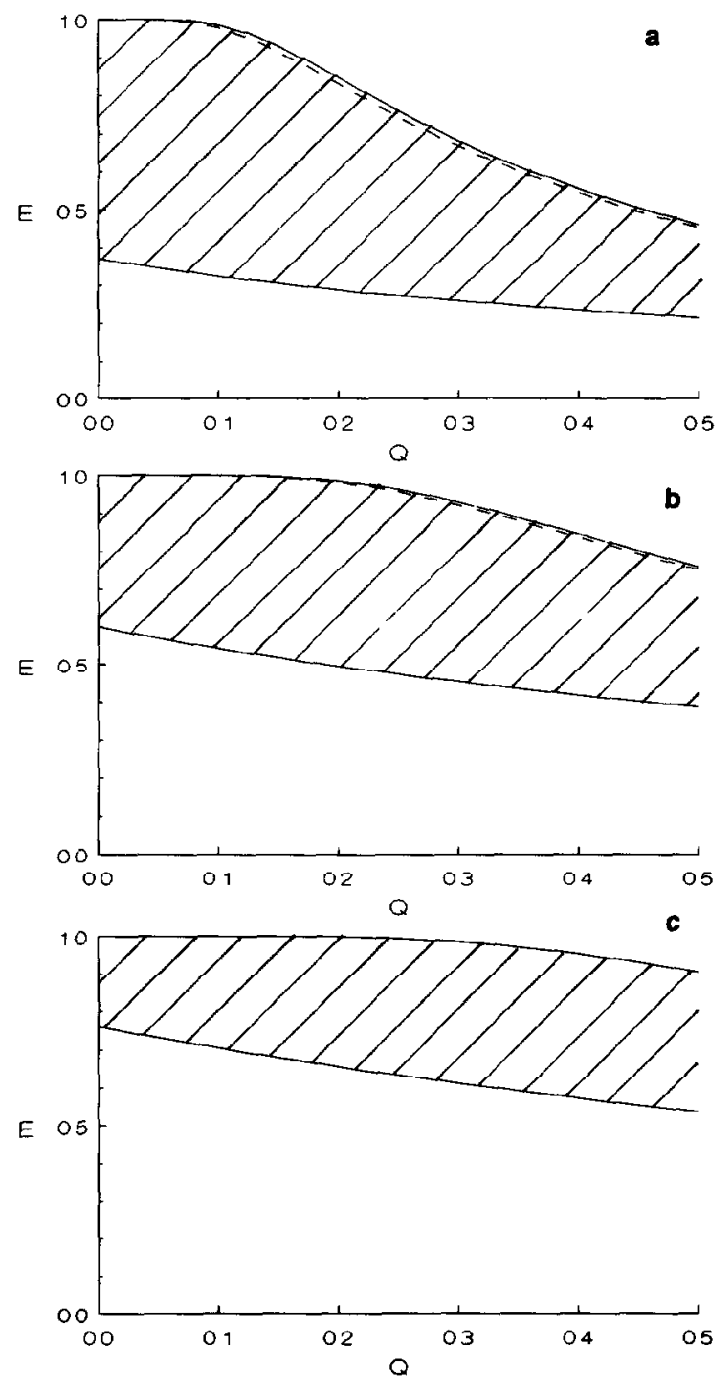

Fig 2 Range within which the actual degree of transfer of a parallel-plate dialyser is to be expected as a function of $Q$ for $\tau$ values of (a) 10 , (b) 20 and (c) 30 The dashed lines indicate the upper limit for finite values of the Peclet number 
stream at $X=10$ Takıng into account the geometric parameters, the flow-rates and the diffusion and the distribution coefficients of the solute, the range within which $E$ can be expected can be determined by the equations derived above This possibility will be illustrated with the frequently encountered case of parallel-plate dialysers with equal dimensions of both channels ( $1 \mathrm{e}, A=1), U=10$ and with both distribution coefficients $\left(F_{\mathrm{d}}\right.$ and $\left.F_{\mathrm{a}}\right)$ equal to unity Under these conditions, the degree of transfer will depend only on the Fourier number of the donor stream and the ratio $Q=\Delta / D_{\mathrm{md}}$ The influence of $Q$ for different $\tau$ values on the range within which the degree of transfer may occur is illustrated in Fig 2 As can be expected, the upper limit in the presence of axial dispersion (1 e, $P e$ has a finite value) is very close to the absolute upper lımıt correspondıng to ideal plug-flow regime in both channels (Fig 2) For this reason in the characterization of the mass transfer in parallel-plate dialysers, the upper limit for a given gross flow pattern can be assumed to be equal to the corresponding absolute upper limit This result considerably simplifies the determination of the range within which the degree of transfer is to be expected, because a knowledge of the res1dence time distribution in the channels of the dialyser which generally can be obtained only by experiments (e g, by the stimulus-response technique [12]) is not necessary

\section{Conclusions}

The degree of transfer of parallel-plate dialysers used in practice is usually well below unity For this reason, the question of increasing their effectiveness is of considerable importance One of the most straightforward approaches for this is to modify the channels of the dialysers in order to intensify the transverse mass transfer and thus decrease the mass-transfer resistances of the channels This can be done empirically by using numerous modifications of the profiles of the channels However, this approach is usually time consuming and costly Moreover, there is a chance that the optimized version will not be substantially more effective than the original dialyser $A$ possibility for avoiding such a situation is proposed here The results outlined show the range within which the value of the degree of transfer of the dialyser can be calculated by simple relationships without the necessity for any prior knowledge on the residence time distribution in the channels A prerequisite is that the design and operation parameters of a given parallel-plate dialyser and the most important factors for the transfer process ( $1 \mathrm{e}$, physical properties of the membrane and of the flowing solutions in the two channels) are known This result can also be used to evaluate the effectiveness of the dialyser For this purpose, the actual value of the degree of transfer should be experimentally determined and compared with its lower and upper limits already theoretically calculated On the basis of this comparison, a conclusion with respect to the efficiency of the dialyser and the necessity for increasing the transverse convection in its channels (e $\mathrm{g}$, by introducing turbulence promoters or additional bends in the channels) can be drawn Unnecessary optımızation of the hydraulic regime of both channels can be avoided if the exper1mentally determined degree of transfer is close to its theoretical upper limit, which is usually lower than unity

\section{REFERENCES}

1 R B Bird, W E Stewart and E N Lightfoot, Transport Phenomena, Wiley, New York, 1960

2 D O Cooney, S-S Kım and E J Davis, Chem Eng Scl, 29 (1974) 1731

3 J Ruzıcka and EH Hansen, Flow Injectıon Analysis, Wiley, New York, 2nd edn, 1988

4 S D Kolev and W E van der Linden, Anal Chim Acta, submitted for publication

5 S D Kolev and W E van der Linden, Anal Chım Acta submitted for publication

6 A Storck and D Hutın, Electrochım Acta, 26 (1981) 127

7 L Risinger, G Johansson, and T Thorneman, Anal Chım Acta, 224 (1989) 13

$8 \mathrm{MJ}$ van der Waal and IG Racz, J Membr Scı, 40 (1989) 243

9 M J van der Waal, S Stevanovic and I G Racz, J Membr $\mathrm{Scl}, 40$ (1989) 261

10 F B Hildebrand, Advanced Calculus for Applications, Prentice-Hall, Englewood Cliffs, NJ, 1963

11 G A Korn and T M Korn, Mathematical Handbook, McGraw-Hill, New York, 1968

$12 O$ Levenspiel and K.B Bischoff, Adv Chem Eng, 4 (1963) 95 